3 Kistemaker LE, Gosens R. Acetylcholine beyond bronchoconstriction: roles in inflammation and remodeling. Trends Pharmacol Sci 2015; 36: 164-171.

4 Slebos DJ, Klooster K, Koegelenberg CF, et al. Targeted lung denervation for moderate to severe COPD: a pilot study. Thorax 2015; 70: 411-419.

5 Powrie DJ, Wilkinson TM, Donaldson GC, et al. Effect of tiotropium on sputum and serum inflammatory markers and exacerbations in COPD. Eur Respir J 2007; 30: 472-478.

6 Mayse M, Johnson P, Streeter J, et al. Targeted lung denervation in the healthy sheep model - a potential treatment for COPD. Eur Respir J 2014; 44: Suppl. 58, P943.

7 Pera T, Zuidhof A, Valadas J, et al. Tiotropium inhibits pulmonary inflammation and remodelling in a guinea pig model of COPD. Eur Respir J 2011; 38: 789-796.

8 Kistemaker LE, Bos IS, Hylkema MN, et al. Muscarinic receptor subtype-specific effects on cigarette smoke-induced inflammation in mice. Eur Respir J 2013; 42: 1677-1688.

9 Gwilt CR, Donnelly LE, Rogers DF. The non-neuronal cholinergic system in the airways: an unappreciated regulatory role in pulmonary inflammation? Pharmacol Ther 2007; 115: 208-222.

10 Kistemaker LE, Oenema TA, Meurs $\mathrm{H}$, et al. Regulation of airway inflammation and remodeling by muscarinic receptors: perspectives on anticholinergic therapy in asthma and COPD. Life Sci 2012; 91: 1126-1133.

11 Morice AH, Celli B, Kesten S, et al. COPD in young patients: a pre-specified analysis of the four-year trial of tiotropium (UPLIFT). Respir Med 2010; 104: 1659-1667.

\title{
Poor agreement between chart-based and objectively identified comorbidities of COPD
}

\section{To the Editor:}

Comorbidities contribute significantly to the individual burden of disease in patients with chronic obstructive pulmonary disease (COPD). Their assessment is considered essential for COPD management and is frequently based on data from patients' charts [1]. However, comorbidities are often undiagnosed [2]. Hence, a mismatch between chart-based and objectively identified comorbidities could be anticipated.

The current cross-sectional analyses were based on data collected in the Centre of Expertise for Chronic Organ Failure (CIRO) Comorbidity study (Maastricht University Medical Centre ethics committee approval number 10-3-067). 11 clinically relevant chart-based and objectively identified comorbidities were assessed in a cohort of patients with clinically stable COPD referred for pulmonary rehabilitation. Patients with a history of asthma, $\alpha_{1}$-antitrypsin deficiency, any previous lung surgery, active inflammatory disease, acute myocardial infarction within the last 6 months, any known bone disease other than osteoporosis, current or recently (i.e. 5 years before the study) treated malignant disease, or use of high-dose systemic glucocorticosteroids (>10 mg prednisolone) were excluded.

Comorbidities were identified objectively, based on predefined cut-offs: chronic kidney disease (estimated glomerular filtration rate $<60 \mathrm{~mL} \cdot \mathrm{min}^{-1}$ (Cockroft-Gault formula)) [3]; anaemia (haemoglobin $<8.1 \mathrm{mmol} \cdot \mathrm{L}^{-1}$ in men or $<7.5 \mathrm{mmol} \cdot \mathrm{L}^{-1}$ in women) [4]; hypertension (systolic blood pressure $>140 \mathrm{mmHg}$ or diastolic blood pressure $>90 \mathrm{mmHg}$ ) [5]; low muscle mass (fat-free mass index $<16 \mathrm{~kg} \cdot \mathrm{m}^{-2}$ for men or $<15 \mathrm{~kg} \cdot \mathrm{m}^{-2}$ for women) [6]; diabetes mellitus (fasting plasma glucose $\geqslant 7.0 \mathrm{mmol} \cdot \mathrm{L}^{-1}$ ) [7]; dyslipidaemia (low-density lipoprotein (LDL)-cholesterol $\geqslant 2.5 \mathrm{mmol} \cdot \mathrm{L}^{-1}$ [8]; osteoporosis ( $\mathrm{t}$-score $<-2.5$ ) [9]; symptoms of anxiety and depression (Hospital Anxiety and Depression Scale (HADS) score $\geqslant 10$ ) [10]; atherosclerosis (carotid intima-media thickness $>0.9 \mathrm{~mm}$ ) [5]; and myocardial infarction (cardiac infarction injury score >20) [11]. The technical details of these assessments have been published previously [12].

Chart-based comorbidities were assessed by combining the medical history recorded in the chest physician's referral letter, the patient's interview and an overview of current pharmacological therapy provided by the patient's pharmacist. Chart-based atherosclerosis was defined as ischaemic cerebrovascular disease, coronary artery disease, peripheral arterial disease and/or aortic aneurysms. Concerning pharmacotherapy, the use of angiotensin-converting enzyme inhibitors, angiotensin receptor blockers, calcium channel blockers, $\beta$-blockers or diuretics was labelled as hypertension; oral antidiabetics or insulin as diabetes mellitus; lipid-lowering drugs as dyslipidaemia; bisphosphonates as osteoporosis; anxiolytics or sedatives as anxiety; antidepressants as depression; and platelet aggregation inhibitors (used only for secondary prophylaxis in the Netherlands) [13] as atherosclerosis. Chart-based and objective assessments were independently recorded and assessed. Combined comorbidity was defined by the presence of chart-based and/or objectively identified comorbidity 
within a single patient. Statistics were performed using SPSS 19.0 (IBM, Armonk, NY, USA). Cohen's $\kappa$ was used to assess the agreement between chart-based and objectively identified comorbidities. $\kappa$-values were categorised as having poor $(<0.40)$, fair to good $(0.40-0.75)$ and excellent $(>0.75)$ agreement [14]. The prevalence of comorbidities was measured. The frequency of objectively identified disease in the presence of chart-based disease was recorded and vice versa. If data were missing, the case was excluded from all analyses.

The final study sample consisted of 213 patients with moderate to very severe COPD (Global Initiative for Chronic Obstructive Lung Disease stages II-IV), substantial smoking history, moderately impaired diffusion capacity and increased static lung volumes, as described previously [12]. Disease frequencies differed between chart-based and objectively identified comorbidities. In turn, a poor level of agreement was found between the methods (figure 1a). Figure $1 \mathrm{~b}$ shows the frequency of chart-based disease in the presence of objectively identified disease, and vice versa.

Poor agreement was observed between the assessment of 11 clinically important comorbidities by objective disease criteria and chart-based diagnoses. The absence of chart-based disease in patients with objectively identified disease is often caused by undiagnosed disease, disregard for poor communication with the patient and between healthcare levels [15], or false positive test results. Undiagnosed comorbidity is common in patients with COPD [2] and could result from the absence or overlap of symptoms, barriers to seeking medical attention, the lack of a standardised diagnostic approach to assess comorbidities [15], or the patient's and physician's perception about a comorbidity (e.g. for muscle wasting). The reason for the absence of objectively identified disease in patients with chart-based identified disease is multifactorial, including old or incorrect chart-based diagnoses (e.g. depression 20 years ago), treatment effect (e.g. by lipid-lowering drugs), the choice of diagnostic criteria and the method of assessment (e.g. absence of ischaemic ECG changes in patients with a prior myocardial infarction).

Chronic kidney disease and anaemia were severely underreported. Objective laboratory testing offers an easily performed, thorough assessment for both diseases. Hypertension, dyslipidaemia and diabetes mellitus were also severely underreported. However, many patients with chart-based disease did not have objectively identified disease, possibly due to treatment. Still, $51.0 \%$ of all subjects previously diagnosed with or treated for hypertension had persistent hypertension. Similarly, $30.6 \%$ of all subjects with chart-based dyslipidaemia had LDL-cholesterol $\geqslant 2.5 \mathrm{mmol} \cdot \mathrm{L}^{-1}$. For these comorbidities, chart-based assessment and objective measurements are probably best combined.

15 out of 19 patients with ECG changes compatible with myocardial infarction did not have chart-based disease, indicating the need for objective testing in addition to chart-based assessment. The mismatch between objectively identified and chart-based atherosclerosis is not surprising as carotid intima-media thickness is a measure of subclinical atherosclerosis, a risk factor for its clinical manifestations.

Although muscle wasting is prevalent and associated with mortality in patients with COPD [6], none of the patients had a chart-based diagnosis, which indicates the need for objective testing of body composition and an increased awareness among physicians. Similarly, $>80 \%$ of all subjects with objectively identified osteoporosis were not previously diagnosed. A large portion of patients with chart-based osteoporosis did not have objectively identified disease. Some patients probably remained undiagnosed if osteoporotic fractures are not taken into account. However, it has been previously reported that patients (with, for example, osteopenia) incorrectly report osteoporosis [9].

Multiple barriers for detection and treatment of mood disorders in patients with COPD have been reported, including patient-perceived, physician-perceived (e.g. short consultation time) and system-level barriers [15]. Under-recognised depression and anxiety symptoms may have deleterious effects on physical functioning, social interaction and healthcare utilisation. In this study, less than one-third of patients with a HADS test indicating anxiety or depression had chart-based disease. Recognition of these symptoms is a first step in breaking barriers to detection of mood disorders. The HADS is a recommended screening tool for anxiety and depression in patients with COPD [15]. However, diagnosing psychological pathology requires more extensive clinical diagnostics.

This study has several limitations. The current findings should not be extrapolated to COPD patients with mild airflow obstruction. The assessment of the pharmacological therapy for chart-based disease is arbitrary. Potential selection bias could be based on the exclusion of patients ineligible for pulmonary rehabilitation. Nevertheless, it was previously demonstrated that the Charlson comorbidity index score in the CIRO Comorbidity study is comparable to other published cohorts [12]. This was a cross-sectional study, not providing any longitudinal information. Finally, the inter-agreement of assessment for these comorbidities cannot reliably be extrapolated to different methods of assessment.

In conclusion, poor agreement exists between objectively identified and chart-based comorbidities. Objective testing seems necessary because comorbidities are severely underreported in patients with 

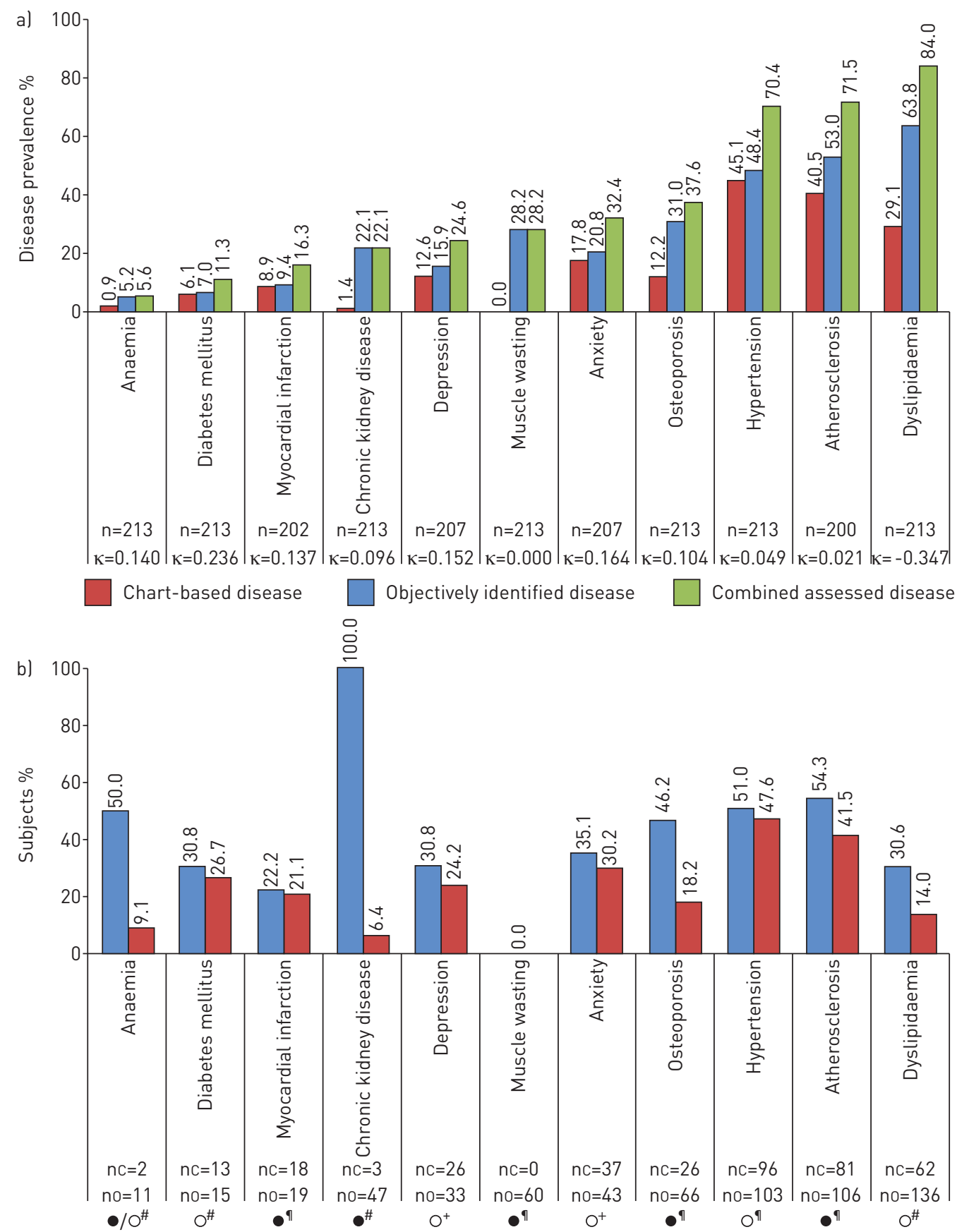

Known chart-based/self-reported diagnosis, in whom the diagnosis could also be objectively identified

Objectively identified comorbidity, who were previously known with this chart-based diagnosis

O Modifiable

- Nonmodifiable

FIGURE 1 The prevalence and agreement of chart-based and objectively identified comorbidities. a) Cohen's $\kappa$ for agreement and the prevalence of chart-based (red) and objectively identified comorbidities (blue). The right-hand column (green) shows the combination of both methodologies for each comorbidity, i.e. the presence of chart-based or objectively identified comorbidity within a single patient. b) Frequency of objectively identified disease in subjects known to have chart-based disease (red) and that of previously known chart-based disease in subjects who were objectively identified with this comorbidity (blue). Excluded from all analyses: 13 patients lacked acceptable quality carotid intimamedia thickness measurement, 11 lacked an acceptable ECG and six did not fill out the Hospital Anxiety and Depression Scale questionnaire. nc: number of patients with chart-based disease; no: number of patients with objectively identified disease. ": based on laboratory value; ": based on technical assessment; ${ }^{+}$: based on a questionnaire. 
COPD. Conversely, clinicians should actively search for signs and symptoms of impactful comorbidities, such as cardiovascular disease and mood disorders. Treatment effects (e.g. for dyslipidaemia, hypertension and diabetes mellitus) and the limitations of the methods of assessment should be considered for research based on objective testing and might necessitate an additional chart-based diagnosis.

0 @ERSpublications

There is poor agreement between chart-based and objectively identified comorbidities in patients with COPD http://ow.ly/QCgf3

Filip J.J. Triest ${ }^{1,2}$, Frits M.E. Franssen ${ }^{1,2}$, Martijn A. Spruit ${ }^{1}$, Miriam T.J. Groenen ${ }^{1}$, Emiel F.M. Wouters ${ }^{1,2}$ and Lowie E.G.W. Vanfleteren ${ }^{1,2}$

${ }^{1}$ Department of Research and Education, CIRO (Centre of Expertise for Chronic Organ Failure), Horn, The Netherlands. ${ }^{2}$ Department of Respiratory Medicine, Maastricht University Medical Centre (MUMC+), Maastricht, The Netherlands.

Correspondence: Filip J.J. Triest, Department of Research and Education, CIRO, PO Box 4080, 6080 AB Haelen, The Netherlands. E-mail: filiptriest@hotmail.com

Received: Jan 132015 | Accepted after revision: July 082015 | First published online: Sept 042015

Conflict of interest: Disclosures can be found alongside the online version of this article at erj.ersjournals.com

\section{References}

1 Divo M, Cote C, de Torres JP, et al. Comorbidities and risk of mortality in patients with chronic obstructive pulmonary disease. Am J Respir Crit Care Med 2012; 186: 155-161.

2 Vanfleteren LE, Franssen FM, Uszko-Lencer NH, et al. Frequency and relevance of ischemic electrocardiographic findings in patients with chronic obstructive pulmonary disease. Am J Cardiol 2011; 108: 1669-1674.

3 KDOQI. KDOQI Clinical Practice Guidelines and Clinical Practice Recommendations for Diabetes and Chronic Kidney Disease. Am J Kidney Dis 2007; 49: Suppl. 2, S12-S154.

4 World Health Organization. Nutritional anaemias. Report of a WHO scientific group. World Health Organization technical report series. Geneva, WHO, 1968.

5 Mansia G, De Backer G, Dominiczak A, et al. 2007 ESH-ESC Guidelines for the management of arterial hypertension: the task force for the management of arterial hypertension of the European Society of Hypertension (ESH) and of the European Society of Cardiology (ESC). Blood Press 2007; 16: 135-232.

6 Schols AM, Broekhuizen R, Weling-Scheepers CA, et al. Body composition and mortality in chronic obstructive pulmonary disease. Am J Clin Nutr 2005; 82: 53-59.

7 American Diabetes Association. Diagnosis and classification of diabetes mellitus. Diabetes Care 2010; 33: Suppl. 1, S62-S69.

8 European Association for Cardiovascular Prevention and Rehabilitation, Reiner Z, Catapano AL, et al. ESC/EAS Guidelines for the management of dyslipidaemias: the Task Force for the management of dyslipidaemias of the European Society of Cardiology (ESC) and the European Atherosclerosis Society (EAS). Eur Heart J 2011; 32: 1769-1818.

9 Stuart AL, Williams LJ, Brennan SL, et al. Poor agreement between self-reported diagnosis and bone mineral density results in the identification of osteoporosis. J Clin Densitom 2015; 18: 13-16.

10 Zigmond AS, Snaith RP. The hospital anxiety and depression scale. Acta Psychiatr Scand 1983; 67: 361-370.

11 Rautaharju PM, Warren JW, Jain U, et al. Cardiac infarction injury score: an electrocardiographic coding scheme for ischemic heart disease. Circulation 1981; 64: 249-256.

12 Vanfleteren LE, Spruit MA, Groenen M, et al. Clusters of comorbidities based on validated objective measurements and systemic inflammation in patients with chronic obstructive pulmonary disease. Am J Respir Crit Care Med 2013; 187: 728-735.

13 Banga JD, van Dijk JL, van Dis I, et al. Cardiovasculair risicomanagement (eerste herziening) [Cardiovascular risk management (first revision)]. Huisarts Wet 2012; 55: 14-28.

14 Fleiss JL. Statistical methods for rates and proportions. 2nd edn. New York, Wiley, 1981.

15 Maurer J, Rebbapragada V, Borson S, et al. Anxiety and depression in COPD: current understanding, unanswered questions, and research needs. Chest 2008; 134: Suppl., 43S-56S. 